\title{
‘IDEOLOGIA DE GÊNERO' E A POLÍTICA DE EDUCAÇÃO NO BRASIL: EXCLUSÃO E MANIPULAÇÃO DE UM DISCURSO HETERONORMATIVO
}

\section{Resumo}

Neste artigo, realiza-se uma análise crítica feminista da manipulação do discurso «ideologia de gênero» em torno da aprovação da Base Nacional Comum Curricular no Brasil. O argumento desenvolvido busca afirmar que o olhar de estranhamento para o/a Outro/a é basilar no modo como a manipulação desse discurso coloca a centralidade da heteronormatividade do gênero na política de educação. Busca ainda demonstrar como essa centralidade está presente na aprovação final do documento com a exclusão da temática de gênero e sexualidade. Por fim, essa abordagem busca somar-se ao conjunto de outros trabalhos que se colocaram na esteira da resistência acadêmica contra a onda conservadora no Brasil.

Palavras-chave: Sexo, sexualidade, identidade de gênero, educação escolar, Base Nacional Comum Curricular do Brasil.

\begin{abstract}
«Gender Ideology» and education policy in Brazil: Exclusion and manipulation of a heteronormative speech

This article makes a critical feminist analysis of the manipulation of the discourse "gender ideology» around the approval of the Common National Curriculum Base in Brazil. The argument here developed seeks to affirm that the look of estrangement towards the Other is fundamental in the way in which the manipulation of this discourse raises the centrality of the heteronormativity of gender in education policy. It also seeks to demonstrate how this centrality is present in the final approval of the document with the exclusion of the theme of gender and sexuality. Finally, this approach seeks to join the set of other works that continue on the path of academic resistance against the conservative wave in Brazil.
\end{abstract}

Keywords: Sex, sexuality, gender identity, school education, Brazilian Common National Curriculum Base.

Resumen

«Ideología de género» y la política de educación en Brasil: exclusión y manipulación de un discurso heteronormativo

En este artículo se realiza un análisis crítico feminista de la manipulación del discurso «ideología de género» en torno a la aprobación de la Base Nacional Común Curricular en

Escola Normal Superior da Universidade do Estado do Amazonas, 69050-010 Manaus, Brasil. Doutoranda em Estudos Feministas na Faculdade de Letras da Universidade de Coimbra, 3004-530, Portugal.

Endereço postal: Av. Djalma Batista, 3578 - Flores - CEP 69050-010 Manaus. Brasil.

Endereço eletrónico: pfrodrigues@uea.edu.br 
Brasil. El argumento desarrollado busca afirmar que la mirada de extrañamiento hacia el/la Otro/a es fundamental en el modo cómo la manipulación de ese discurso plantea la centralidad de la heteronormatividad del género en la política de educación. También busca demostrar cómo esta centralidad se encuentra presente en la aprobación final del documento con la exclusión de la temática de género y sexualidad. Por último, este enfoque busca sumarse al conjunto de otros trabajos que se colocaron en el camino de la resistencia académica contra la ola conservadora en Brasil.

Palabras clave: Sexo, sexualidad, identidad de género, educación escolar, Base Nacional Común Curricular de Brasil.

\section{Introdução}

Qual o lugar da centralidade da heteronormatividade do gênero na política pública de educação no Brasil? Recentemente, esteve em discussão no Brasil a terceira versão da Base Nacional Comum Curricular (BNCC) que trata de uma política pública que estabelece as diretrizes para a educação básica escolar em todo o país, e sua finalização ocorreu em dezembro de 2017. Um dos pontos mais polemizados do documento foi em torno da temática de gênero e orientação sexual, em que o discurso «ideologia de gênero» ganhou maior expressão de tensões.

A atual discussão no Brasil em torno da política pública em educação tem convergido para o tema de gênero ${ }^{1}$ e sexualidade como o mais polemizado desde a última elaboração do Plano Nacional de Educação no ano de 2014. Nesse contexto, emergiu de forma muito expressiva o discurso «ideologia de gênero» como o emblema dos grupos contrários ao tema «identidade de gênero e orientação sexual» nos documentos das políticas de educação em elaboração no país. ${ }^{2}$ Tal discurso tem um tom fortemente acusador nas diferentes maneiras como é empregado para afirmar que se trata de um tema que atentaria contra a «ordem natural» dos corpos e, portanto, perigoso/ameaçador para estar nos currículos escolares. Nas audiências públicas sobre a Base Nacional Comum Curricular realizadas no ano de 2017, novamente vários grupos se organizaram para afirmar contra a temática de gênero e sexualidade na educação. Por exemplo, na audiência pública em Manaus, realizada no mês de julho, um discurso muito repetido foi que esse tema levava «a perda da identidade»: «toda essa ideologia tem o objetivo da promoção da perda da identidade desde a infância que é direito das famílias estarem presente nessa decisão». ${ }^{3}$ Em Florianópolis, audiência realizada no mês de agosto,

Ver Vianna e Unbehaum (2004) sobre o gênero na política pública em educação de 1988 a 2002 no Brasil.

2 Ver Reis e Eggert (2017) para um panorama das discussões atuais em que o discurso «ideologia de gênero» tem emergido nos planos de educação.

3 O trecho é de uma fala de uma profissional liberal, Vanessa Estone, na audiência pública de Manaus que pode ser conferida na íntegra no vídeo gravado (1:42) pela TV MEC e de acesso pelo youtube: $<$ https://www.youtube.com/watch? $=$ oWgjQ807gpA $>$. 
novamente essa questão com ênfase aos termos homem e mulher: «a ideologia de gênero [...] é uma desconstrução das identidades, onde os professores vão ensinar os seus filhos [...], eles vão ser questionados se eles são de fato homens, se eles são de fato mulheres». ${ }^{4}$ Essas falas refletiram a tônica no modo como a manipulação do discurso «ideologia de gênero» ocorreu ao longo do processo de finalização do documento dessa política pública.

Face a esse processo, o qual finalizou com a aprovação do documento final da Base Nacional Comum Curricular sem nenhuma menção a gênero social ou orientação sexual, me interessa perceber como o discurso «ideologia de gênero» foi um forte instrumento político ideológico da heteronormatividade de gênero. Assim, o objetivo desse artigo explora como a manipulação do discurso «ideologia de gênero» apresenta um olhar de estranhamento para aquelas e aqueles que não se ajustam à norma heterossexual voltada para a reprodução e como esse olhar, também excludente e ideológico, está presente no documento da Base Nacional Comum Curricular.

O aporte teórico no qual desenvolvo esse trabalho busca a teoria de Judith $\operatorname{Butler}^{5}$ ([1990] 2016) no entendimento de que as identidades de gênero não são fixas e imutáveis, de que não há um modelo único de gênero possuidor de uma «essência verdadeira» que defina sobre ser mulher ou homem, mas, sim, que é de caráter performativo, da repetição estilizada de atos para construir o gênero, sem que este exista como verdadeiro ou falso. A escolha dessa perspectiva teórica se fez importante em face da tendência manipuladora do discurso «ideologia de gênero» ter voltado a temática de gênero e sexualidade na política de educação principalmente para uma questão de identidade de gênero e contra a homossexualidade. Também busco essa autora por ter sido a sua teoria citada em falas durante as audiências públicas de uma maneira extremamente equivocada, e considero esse artigo um espaço oportuno para contrapor a manipulação do discurso «ideologia de gênero» que se tornou em um emblema dos defensores da heteronormatividade do gênero. Busco a perspectiva teórica do gênero performativo também em Guacira Louro $(2000,2014)$ que o coloca como uma questão crítica a ser trabalhada no contexto da educação, uma vez que as escolas são espaços de diversidade e querer homogeneizá-las é uma forma de ignorar a realidade, silenciar e mesmo

O trecho é de uma fala de uma assessora parlamentar, Geane Vieira, na audiência pública de Florianópolis que pode ser conferida na íntegra no vídeo gravado (1:06) pela TV MEC e de acesso pelo youtube: $<$ https://www.youtube.com/watch?v=9KNhkDFp8Jk $>$.

5 Judith Butler esteve no Brasil para lançar o seu mais recente livro e participar do seminário «Os fins da democracia» no dia 7 de novembro de 2017 e foi alvo de ataques de grupos conservadores que levaram um boneco com a foto da autora e o queimaram como analogia de queima às bruxas. Ela depois deu entrevista e produziu um vídeo de resposta ao lamentável ocorrido (disponível em https://brasil.elpais.com/brasil/2017/11/08/politica/1510163007_290424. html?id _externo_rsoc=FB_BR_CM [Consultado a 11/11/2017] e https://www.revistaforum.com. br/2017/11/13/judith-butler-responde-aos-ataques-de-odio-nos-temos-alegria-e-liberdade-donosso-lado/ [Consultado em 25/11/2017]. 
eliminar aquelas e aqueles que não estão em conformidade ao modelo dominante da heteronormatividade do gênero.

O artigo está organizado em dois momentos, no primeiro, realizo uma análise crítica de como o olhar de estranhamento para o/a Outro/a é um aspecto basilar no modo como se manipula o discurso «ideologia de gênero» voltado principalmente para estigmatizar, discriminar, a homossexualidade. No segundo momento, realizo uma crítica no modo como a manipulação ideológica do discurso «ideologia de gênero» em defesa de uma suposta «evidência» do gênero e uma falsa neutralidade política está presente no documento aprovado da Base Nacional Comum Curricular.

\section{Olhar o/a Outro/a: o processo civilizatório do sexo}

Os aspectos binários em que o modo de manipular o discurso «ideologia de gênero» se mostram predominantes no Brasil dão um exemplo de como a política pública de educação no atual governo reflete processos históricos de exclusão. Desses processos históricos, o olhar colonizador que constrói e homogeneíza o/a Outro/a deixa resquícios de significação cultural e política para com o diferente, e uma forma de pensamento estreitamente relacionada com a moral religiosa cristã tem reforçado a ênfase na vigilância normatizadora sobre os corpos. Desse modo, retomo a crítica desse olhar como um caráter da heteronormatividade presente na campanha contra a temática de gênero e orientação sexual na Base Nacional Comum Curricular.

Aquando do estranhamento do olhar do viajante europeu para os chamados povos do Novo Mundo uma indagação preocupante se fez em relação àqueles seres, qual seja, se seriam eles/elas humanos/as. Pareciam homens e mulheres, nos sexos à mostra. Mas o olhar não necessariamente vê, e estavam convencidos de que era preciso trazer a civilização para o novo mundo deles - dos viajantes. Esse olhar que construiu o Outro no Novo Mundo consolidou um modo discursivo não apenas de denominar, mas principalmente, de criar àqueles/as classificados/as como um tipo de seres humanos estranhos. Em parte, pode-se dizer que o quadro de significação do Outro pelo olhar europeu não é sexuado, pelo menos enquanto indistintamente o Outro é apenas de raça inferior, à margem da civilização e, ainda, fadado ao desaparecimento histórico, mas considerando que o aspecto do gênero é sexuado, na medida em que os corpos das mulheres foram submetidos à política de ocupação dos territórios na violência física e cultural. Stolcke ([2003] 2006) afirma que a construção da sociedade colonial pelos impérios de Espanha e Portugal ocorreu na interseção entre classe, raça e sexualidade, no controle da sexualidade das mulheres. Por exemplo, os corpos das mulheres, no projeto colonizador do chamado Novo Mundo, foram atrelados à reprodução sob o código moral da virgindade controlada pelos homens da elite colonial. O que foi de grande importância no projeto civilizatório da sociedade colonial, «em que o corpo 
sexuado tornou-se fundamental na estruturação do tecido sociocultural e ético engendrado pela conquista europeia» (Stolcke 2006 [2003], 16). Portanto, a política civilizatória para o chamado Novo Mundo construiu a raça e utilizou os corpos das mulheres como o território de poder do homem ocidental, branco, heterossexual, dito civilizado. «O gênero não trata de mulheres como tais. Refere-se aos conceitos que prevalecem em uma sociedade sobre o que são as mulheres em relação aos homens enquanto seres humanos sexualmente identificados» (17). Contudo, é importante pontuar que não tenho a intenção de reproduzir uma passividade e mera aceitação do controle sexual e reprodutivo pelas mulheres do olhar colonizador, mas descrever um traço do projeto civilizatório em que o sexo/gênero foi significativo nas relações de poder na perspectiva da heteronormatividade. Nesse sentido, também o gênero foi uma construção pela exotização do olhar os corpos, mas sem realmente os ver. Qual o legado do sentido histórico desse olhar sobre o corpo sexuado? Penso que essa pergunta desencadeia para várias respostas, mas buscarei me comprometer aqui em afirmar que um segundo quadro de significação do Outro em relação ao corpo sexuado será o modo de olhar outras sexualidades que não tenham a prática sexual em conformidade com a norma do dimorfismo sexual orientada para a reprodução.

Há dois aspectos importantes a serem considerados aqui, primeiro, certamente que um processo histórico deve ser notado, uma vez que aponto uma consequência que parte do olhar heterossexual sobre os corpos das mulheres para o corpo sexuado na questão da homossexualidade. Segundo, o do contexto sociocultural em que a questão mais ampla é o da sexualidade como norma não apenas de moral religiosa, mas também de moral laica em que a heterossexualidade servia ao viés da dominação dos corpos e marginalizava outras sexualidades.

Não é sem problemas que olhar para trás na história em relação à sexualidade é complicado, principalmente quando é desde o ponto de vista dos preconceitos do presente que se pretende compreender como chegámos ao momento em que se tenta eliminar a homossexualidade, por exemplo, pela heterossexualidade imposta como «ordem natural» do ser humano. Penso que o/a Outro/a sexuado/a no que diz respeito à homossexualidade estava presente aquando das diferentes formas negativas em que aparece nos registros históricos, principalmente pelo olhar religioso cristão no mundo ocidental. ${ }^{6}$ Historicamente as práticas sexuais consideradas desviantes da norma heterossexual também foram perseguidas pelos tribunais de inquisição católica no Brasil. ${ }^{7}$ Por exemplo, essas formas negati-

6 Não desconsidero que outras religiões, não apenas a cristã, tenham também um olhar negativo para a sexualidade diferente da heterossexualidade. Contudo, me refiro tão somente à cristã porque nesse contexto histórico da colonização do Brasil foi essa a religião predominante no processo de dominação cultural dos povos autóctones pela catequização cristã católica, bem como tem sido dominante até hoje na política do país.

7 Uma referência histórica sobre a sexualidade no Brasil é Ronaldo Vainfas (2010). Não busquei aprofundar historicamente exemplos específicos que pudessem ilustrar aqui alguns fatos, pois isso abriria a discussão para outras questões diferentes do tema explorado no artigo. 
vas diziam respeito, e ainda dizem, à ideia de pecado e à prática sexual não direcionada à procriação. Posso citar ainda que há pouco tempo a proposta da chamada «cura gay» foi propagada no país por setores de religião cristã evangélica. ${ }^{8}$ É verdade que há grupos pertencentes às religiões cristãs que são dissidentes dessa visão excludente da sexualidade, portanto, o que tenho em consideração como crítica é o grupo dominante aliado à política conservadora do atual governo. Assim, a perseguição contra a homossexualidade tem o aspecto do olhar estranhado uma vez que na construção da norma moral, política e institucional da heteronormatividade o que está em causa é aquela/aquele que não se ajusta à sua imposição do humano idealizado.

Foucault ([1976] 2015) historiciza o sexo que no processo civilizatório do ocidente foi colocado dentro do quarto e debaixo dos lençóis, mas criando a comichão por olhar pela fechadura da porta. Como afirma Foucault «a sexualidade é o nome que se pode dar a um dispositivo histórico: [...] a incitação ao discurso, a formação dos conhecimentos [...] segundo algumas grandes estratégias de saber e poder» ([1976] 2015, 115). Qual o lugar da fala desses sujeitos dos discursos? Vemos no Brasil que os principais manipuladores do discurso «ideologia de gênero» têm forte representação na esfera política do país e assistimos como as chamadas bancadas evangélica e católica no congresso brasileiro têm forte atuação contra as políticas públicas de educação que buscam incluir a temática de gênero e orientação sexual no ensino escolar. Como a expressão deixa claro, são representantes de segmentos religiosos e não de toda a sociedade brasileira. ${ }^{9} \mathrm{O}$ discurso «ideologia de gênero» quer ter uma onipresença como se refletisse a sociedade mesma, não mais falacioso do que os grupos em tom aparentemente unívoco e repetitivo que ao dizerem «contra» têm em causa os seus próprios interesses políticos. ${ }^{10}$

A esteira política e o poder foi onde o gênero e o sexo foram situados, a conceituação de Scott busca demonstrar isso, ao afirmar que «o gênero é um elemento

8 Em 2015 o deputado Pastor Marco Feliciano (PSC-SP) deu início a uma campanha para defender a chamada «cura gay». Em 2013 o mesmo deputado tinha proposto um projeto de lei para autorizar a suposta cura, mas que não passou no Congresso. E ainda, no ano de 2014, outro parlamentar, deputado Pastor Eurico (PSB-PE), novamente propõe um projeto semelhante, que foi retirado depois pelo próprio partido.

9 No ano de 2011, na gestão da Presidenta Dilma, foi realizado um projeto intitulado «Brasil sem homofobia», elaborado em 2004, e uma parte dele era direcionado para professores/as das escolas e dele resultou um material que seria distribuído na rede pública de ensino. Mas, as bancadas evangélica e católica pressionaram o governo pela retirada da distribuição do material e propagaram a expressão kit gay nos meios de comunicação, gerando distorções e polêmicas à época no país.

10 Daria um outro trabalho falar dos sujeitos e grupos políticos que dão a tônica do discurso «ideologia de gênero», mas apenas para lembrar que a relação entre religião e política se faz de modo visceral nas relações de poder no país, e nos últimos anos têm ganhado muita expressão no congresso brasileiro ao defenderem posições conservadoras contra o acesso à democracia em relação às questões de gênero na educação. 
constitutivo de relações sociais baseado nas diferenças percebidas entre os sexos, e [...] uma forma primeira de significar as relações de poder» ([1988] 1995, 21), o que envolve também a sexualidade. Contudo, tal centralidade primeira do gênero desde a década de 1980 para cá, pouco mais da primeira década do século XXI, esteve em questionamento já pelo feminismo negro, mas também na dinâmica da história em face de outros eixos das relações de poder - complexos, desde o projeto civilizatório do Novo Mundo, mas que a certeza de humanidade civilizante sufocou por vários momentos, sempre que o olhar para o/a Outro/Outra significou não ver. Da conceituação do gênero às problematizações em torno do sexo proliferaram vozes e discursos que fizeram emergir uma politização da sexualidade. Nesse sentido, no contexto da política brasileira atual para o qual quero chamar a atenção, busco problematizar o olhar em que a manipulação do discurso «ideologia de gênero» retoma o estranhamento civilizatório que busca excluir as pessoas que não se adequam ao modelo dominante da heterossexualidade voltada para a reprodução.

A dualidade natureza e cultura é colocada novamente como o pano de fundo em que o/a Outro/a é afastado/a do ambiente da cultura em que o discurso não apenas o nomeia, o classifica, mas, sim, o constrói. A tentativa de uma linha divisória para definir (e quem define?) o que é biológico e o que é cultural é tênue, cambiante, fluida, e o modo como o gênero e o sexo são postos em causa para construir o/a Outro/a é sempre passível de questionamento quando tal tentativa marginaliza, inferioriza, cerceia direitos, estigmatiza e quer lhe impor uma marca patologizante, como o faz a atual manipulação distorcida do discurso «ideologia de gênero» em vários contextos e que tem influenciado a política de educação no Brasil.

Butler ([1990] 2016, 27), ao analisar o conceito de sexo e gênero como categorias históricas, busca desconstruir a relação binária em que o sexo está para a natureza e o gênero para a cultura, o que implica na compreensão de que o corpo não é um recipiente passivo onde simplesmente se inscrevem significados culturais. Assim, a autora afirma que «o corpo é em si mesmo uma construção, assim como o é a miríade de «corpos» que constitui o domínio dos sujeitos com marcas de gênero» (30). A proposta de Butler, ao buscar descontruir o gênero entre o que é ser mulher e ser homem sempre dentro da visão binária, é o da subversão da identidade ou, melhor dizendo, subversões performativas. Não há uma natureza feminina ou masculina na pessoa para além dos atos, gestos e desejos que são reproduzidos na superfície do corpo; atos, gestos e desejos produzem apenas o efeito de uma substância interna, mas são performativos. Não existem gêneros verdadeiros ou falsos, apenas performances produzidas como efeitos da verdade construídos em discursos sobre a identidade. Para além do desconforto que a sua teoria causou desde a década de 1990, e que lhe rendeu várias críticas, nem todas justas e nem coerentes, a questão da performatividade abriu o horizonte para problematizar o olhar sobre os corpos.

A teoria de Butler ([1990] 2016) influenciou o campo da educação e foi tomada como uma forma de pensar uma pedagogia não excludente e dar visibilidade para 
as questões da sexualidade. Uma das contribuições muito significativas no Brasil nessa perspectiva é Guacira Louro $(2000,2014)$ que analisa criticamente como as marcas da escolarização se inscrevem nos corpos dos sujeitos.

Guacira Louro (2000) problematiza a visão binária que incide sobre os corpos numa necessidade de fixar uma identidade imutável sobre os indivíduos e como uma escolarização do corpo pratica uma pedagogia da sexualidade, na medida em que a ação pedagógica tem como investimento mais profundo a formação de mulheres e homens «de verdade». Um corpo escolarizado, como afirma a autora, é assim valorizado pelo que a instituição escola representa para a sociedade, as marcas de um processo civilizador, de mulheres e homens bem-educados nos valores e práticas que constituem o que é ser mulher e homem para essa sociedade.

Se múltiplas instâncias sociais, entre elas a escola, exercitam uma pedagogia da sexualidade e do gênero e colocam em ação várias tecnologias de governo, esses processos prosseguem e se completam através de tecnologias de autodisciplinamento e autogoverno que os sujeitos exercem sobre si mesmos (Louro 2000, 17).

Desse modo, é todo um investimento institucional e incorporada pelos próprios sujeitos por uma identidade de gênero e sexual não desviantes da norma hegemônica da heterossexualidade. Mas aquelas e aqueles que agem diferentes a essa regra serão marcados e marcadas de várias maneiras, seja pela vigilância redobrada, pelo preconceito, pelo estigma, inclusive com a violência física e o assassinato. São essas as maneiras que muitas vezes «orientam» que é melhor esconder, fingir, dissimular sobre a sexualidade e de modo a interferir significativamente em trajetórias de sexualidades das pessoas.

Por que no modo de olhar o humano se quer ignorar a heterogeneidade? $\mathrm{O}$ olhar não é necessariamente ver, e simplesmente não garante a inteligibilidade do que se olha. Mas o quê que não se vê? A manipulação do discurso «ideologia de gênero» quer atribuir um humano idealizado numa representação de homogeneidade imaginária. Ao impor o sentido da construção do/a Outro/a quer trazer um projeto civilizatório do sexo instrumentalizando a política pública de educação no Brasil ao retirar a temática de gênero e orientação sexual na Base Nacional Comum Curricular. O sentido do/a Outro/a que a manipulação do discurso «ideologia do gênero» carrega e marca assim novamente uma diferenciação hierárquica entre as pessoas, mas não somente. Disso decorre que no contexto brasileiro tal perspectiva é político-ideológica e reflete, em parte, um modelo de pensamento binário, mas também a dominação por uma não historicização do sexo/gênero. Portanto, $\mathrm{o}$ modo como o texto final da Base Nacional Comum Curricular foi aprovado, com a exclusão da temática gênero e orientação sexual, expressa a imposição de um projeto civilizatório de caráter heteronormativo. 


\section{Formas discursivas de exclusão do/a Outro/a na Base Nacional Comum Curricular}

O caráter heteronormativo em que a campanha contra a temática de gênero e orientação sexual foi propagada na manipulação do discurso «ideologia de gênero» reflete uma estratégia político discursiva dos grupos conservadores no Brasil aliados com o atual governo. A falsa neutralidade dos propagadores de tal discurso esteve enredada principalmente em uma moral religiosa cristã e laica, uma vez que as contradições da realidade brasileira para com as questões de gênero não tiveram atenção no mesmo nível de importância em que se polemizou o discurso «ideologia de gênero». Nesse sentido, busco tratar das formas discursivas em que tal discurso foi manipulado para a exclusão da temática gênero e orientação sexual na Base Nacional Comum Curricular.

O discurso ideológico que manipula uma «ideologia de gênero» acentua principalmente um processo de eliminação. De acordo com Foucault ([1970] 1999, 9-10) o discurso é produzido e ao mesmo tempo controlado, selecionado, organizado e redistribuído por certos procedimentos de exclusão. A exclusão que a manipulação do discurso «ideologia de gênero» opera é a do princípio da interdição ao afirmar contra o tema de gênero e orientação sexual na Base Nacional Comum Curricular da política de educação no Brasil. Aqui é preciso ainda pensar se não seria esse discurso uma forma de violência e como ela está sendo institucionalizada, pois a escola é o principal lócus desse processo de interdição. É nesse sentido que Louro, ao analisar a produção da diferença na prática educativa escolar no uso da linguagem, chama a atenção ao ocultamento dos/as homossexuais e da homossexualidade pela escola. «Ao não se falar a respeito deles e delas, talvez se pretenda «eliminá-los/as», ou pelo menos, se pretenda evitar que os alunos e as alunas «normais» os/as conheçam e possam desejá-los/as» (2014, 71-72). Tal suposta ideia de normalidade revela ainda que esse discurso vincula o sentido de uma autoridade moral que busca regular sobre práticas sexuais consideradas desviantes da norma heterossexual dominante.

Assim, o documento da Base Nacional Comum Curricular espelha como os modos da manipulação do discurso «ideologia de gênero» vincularam a proibição e a autoridade moral para afirmar a heteronormatividade na política de educação. A garantia da «norma» no documento da BNCC, portanto, limita a sexualidade à prática heterossexual e reprodutiva. No último documento que produziu, os componentes curriculares do $6 .^{\circ}$ ao $9 .^{\circ}$, a sexualidade aparece no componente curricular Ciências, especificamente na unidade temática vida e evolução, e afirma:

Pretende-se que os estudantes, ao terminarem o Ensino Fundamental, estejam aptos a compreender a organização e o funcionamento de seu corpo [...]. É também fundamental que tenham condições de assumir o protagonismo na escolha de posicionamentos que representem autocuidado com seu corpo e respeito com o corpo do outro, na perspectiva do cuidado integral à saúde física, mental, sexual e reprodutiva (Brasil, 2017, 279; grifos meus). 
A passagem tem uma mensagem muito clara sobre o modo como o discurso propagado como «ideologia de gênero» prevaleceu no sentido de eliminar quaisquer possibilidades de questionar o pensamento binário e excludente no qual a forma discursiva se apoiou para construir o/a Outro/a. Mais evidente ainda está na mudança do texto da terceira versão da Base Nacional Comum Curricular para o texto final aprovado em dezembro de 2017, que trata das habilidades esperadas no componente curricular nos últimos anos do Ensino Fundamental. $O$ texto da terceira versão afirma: «(EF08CI11) Selecionar argumentos que evidenciem as múltiplas dimensões da sexualidade humana (biológica, sociocultural, afetiva e ética) e a necessidade de respeitar, valorizar e acolher a diversidade de indivíduos, sem preconceitos baseados nas diferenças de gênero» (BNCC, Terceira versão, 301, abril de 2017; grifos meus). Mas, o texto do documento final aprovado ficou apenas: «(EF08C111) Selecionar argumentos que evidenciem as múltiplas dimensões da sexualidade humana (biológica, sociocultural, afetiva e ética)» (Brasil 2017, 347). A parte do texto suprimida evidencia a institucionalização da heteronormatividade não apenas como norma, mas como poder que institui um único modelo de humano, de gêneros distintos pelo dimorfismo sexual. Assim, não se trata simplesmente de um debate de ideias quando a manipulação do discurso «ideologia de gênero» constrói o/a Outro/a parte da ideologia de que $o$ gênero é $o$ homem e $a$ mulher, invocando «a evidência» de que $o$ homem tem pênis e $a$ mulher tem vagina, e em uma relação positivista de causa e efeito, o sexo é masculino ou é feminino. Quer submeter o/a Outro/a à ideologia moral ou ideologia religiosa ou ainda à ideologia política como heteronormatividade pela qual indivíduos ou grupos representam tais práticas ideológicas. É a relação imaginária desses indivíduos com as suas condições de existência com o sexo que o colocam na prática da heterossexualidade e como não ideológico. É como o sexo é representado na prática heterossexual que fundamentam uma deformação imaginária no discurso «ideologia de gênero» que interpelam nos/as os/as Outros/as. A evocação da «evidência» no contexto de tal discurso nada mais é do que um efeito ideológico, como afirma Althusser,

é próprio da ideologia impor (sem o parecer, pois que se trata de «evidências») as evidências como evidências que não podemos deixar de reconhecer, e perante as quais temos a inevitável reação de exclamarmos [...]: «é evidente! É isso! Não há dúvida! (Althusser 1980, 95; grifo no original).

Por mais que a manipulação do discurso «ideologia de gênero» pretenda impor um significado em si, como «evidência», a sua pretensa interdição sobre o que pode ou não ser dito, quem pode ou não dizer, sobre o quê que pode dizer e o quê que não pode, demonstra uma preocupação constante em afirmar a constituição de corpos masculinos e femininos heterossexuais em um jogo de poder para sujeitar os corpos a uma identidade ideologicamente fixa.

Butler, ao analisar de maneira crítica as proibições em que o corpo é discursivamente enredado para a produção de uma identidade heterossexual idealizada e compulsória, afirma que: 
Essa produção disciplinar do gênero leva a efeito uma falsa estabilização do gênero, no interesse da construção e regulação heterossexuais da sexualidade no domínio reprodutor. A construção da coerência oculta as descontinuidades do gênero, que grassam nos contextos heterossexuais, bissexuais, gays e lésbicos, nos quais o gênero não decorre necessariamente do sexo (Butler [1990] 2016, 234).

Nesse sentido, é como o ideal regulador da manipulação do discurso «ideologia de gênero» se revelasse como norma e ficção, pois toda a campanha contra a temática de gênero e sexualidade no documento da Base Nacional Comum Curricular ganhou repercussão midiática no país principalmente sendo destacado, e reforçado, o posicionamento político de religiosos políticos. Ao mesmo tempo em que a mesma mídia não problematizava as contradições sociais em que a proibição da temática implica na realidade social brasileira em relação as questões de gênero. É esse sentido de exclusão da vida do/a Outro/a que o discurso ideológico carrega quando do feminicídio, da homofobia, da transfobia, que procura na vítima um comportamento sexual não aceito moralmente pela heteronormatividade para justificar que não sejam vidas dignas de proteção. Por que o modo como o/a Outro/a dispõe do seu próprio corpo desperta o medo e a ansiedade de eliminá-lo/a? A estratégia política do discurso contra a «ideologia de gênero» frequentemente agrega os discursos «em defesa da família», ${ }^{11}$ "pela proteção das crianças», ${ }^{12}$ como um apelo a moral social. Contudo, é com esse mesmo princípio de orientação do comportamento humano que tal discurso hierarquiza os corpos que não estão ajustados ao modelo ideológico de família heteronormativa e nem à prática sexual orientada para a reprodução.

A manipulação do discurso «ideologia de gênero», ao ser contra o tema de gênero e orientação sexual na Base Nacional Comum Curricular, mobiliza uma suposta narrativa de neutralidade educacional, sendo essa forma de apagamento das diferenças - nos modos como as pessoas se percebem em relação ao seu próprio corpo - uma forma de violência, porque tal discurso legitima assim a violên-

11 Discurso que ignora a família como um assunto também de interesse na temática de gênero e sexualidade, e ainda, diante de fatos como o da violência doméstica e familiar. Os resultados da Pesquisa DataSenado de 2017 sobre violência doméstica e familiar contra as mulheres revelaram um aumento do número de mulheres que declaram ter sofrido algum tipo de violência doméstica, de 18\% em 2015 para 29\% em 2017. Disponível em https://www12.senado.leg.br/institucional/datasenado/arquivos/aumenta-numero-de-mulheres-que-declaram-ter-sofrido-violencia [Consultado a 03/02/2018].

12 A hipocrisia contrasta com os dados do Disque Denúncia e divulgados pela Ouvidoria Nacional dos Direitos Humanos, vinculada ao Ministério da Justiça e Cidadania, que no ano 2016 revela que a casa da vítima é o local onde concentra maior porcentagem de violações. O que corrobora com estudos que demonstram que os crimes sexuais contra crianças acontecem dentro da família. Disponível em http://www.sdh.gov.br/disque100/balancos-e-denuncias/balanco-disque100-2016-apresentacao-completa/ [Consultado a 30/12/2017]. 
cia contra as mulheres, ${ }^{13}$ transgêneros, travestis, ${ }^{14}$ gays, lésbicas, e qualquer outro/a que não se veja na ideologia heteronormativa do gênero. Tal narrativa esteve presente, por exemplo, na fala do secretário de Educação Básica do Ministério de Educação, Rossiele Soares da Silva. Em entrevista à Agência Brasil, em setembro de 2017, ele demonstrou a posição do MEC:

O secretário de Educação Básica do MEC explicou que a Base traz uma redação que trata das diversidades de maneira geral, entre elas, as diversidades de gênero, de opção sexual, de etnias. «Nós entendemos que a redação está em um ponto adequado, mas agora cabe ao CNE fazer qualquer apresentação de contraproposta ao Ministério da Educação. Estamos próximos para sentar e discutir todos os temas», disse Silva ${ }^{15}$ (grifos meus).

Mas, o documento final da Base Nacional Comum Curricular não faz nenhuma menção ao respeito à diversidade de gênero.

Como já foi dito, de acordo com Butler ([1990] 2016), o gênero é produzido por atos e gestos performativos que criam o efeito de uma coerência interna através da linguagem que discursivamente tem o propósito de regular a sexualidade no modelo da heterossexualidade reprodutora. Portanto, o modo estratégico em que o discurso «ideologia de gênero» é manipulado busca reforçar justamente esse ideal fantasioso de uma «verdade interna» do gênero ao mesmo tempo em que cria um sistema de exclusão para aqueles/aquelas que não se ajustam a tal modelo. As tramas do poder em que esse discurso é manipulado convergiram para a política de educação na atual aprovação da Base Nacional Comum Curricular porque, ao instituir uma matriz excludente, estabelece a consequente punição daqueles/ daquelas que estão fora da estrutura da heterossexualidade compulsória, e, como afirma Louro (2014, 89), a escola também fabrica sujeitos. Vimos, assim, como o texto final reflete as formas discursivas de interdição em uma suposta ideia de neutralidade, de moralidade, por meio de um discurso ideológico e político que

13 O Brasil é o país com a quinta maior taxa de feminicídio do mundo. As mulheres negras são ainda mais violentadas. Apenas entre 2003 e 2013, houve aumento de 54\% no registro de mortes, passando de 1864 para 2875 nesse período. Muitas vezes, são os próprios familiares $(50,3 \%)$ ou parceiros/ex-parceiros $(33,2 \%)$ os que cometem os assassinatos. Disponível em http://agenciabrasil.ebc.com.br/direitos-humanos/noticia/2017-08/taxa-de-feminicidios-no-brasil-e-quinta-maior-do-mundo [Consultado a 02/01/2018].

14 O Brasil é o país que mais mata travestis e transexuais no mundo, diz pesquisa. Disponível em http://g1.globo.com/profissao-reporter/noticia/2017/04/brasil-e-o-pais-que-mais-mata-travestis-e-transexuais-no-mundo-diz-pesquisa.html [Consultado a 02/02/2018]. O último relatório de violência contra LGBT pela Secretaria dos Direitos Humanos é de 2013. Disponível em http:// www.sdh.gov.br/noticias/2013/junho/numero-de-denuncias-de-violencia-homofobica-cresceu166-em-2012-diz-relatorio [Consultado em 02/02/2018].

15 A entrevista pode ser conferida na íntegra no site da Agência Brasil: <http://agenciabrasil.ebc. com.br/educacao/noticia/2017-09/mec-diz-que-nao-abrira-mao-de-antecipar-alfabetizacao-ate-o-2o-ano. A Empresa Brasil de Comunicação (EBC) é uma empresa pública federal criada pela Lei no 11.652/2008 e alterada pela Lei no 13.417/2017>. 
defende um modelo heterossexual reprodutivo de controle dos corpos. Portanto, o modo como o documento final foi aprovado reflete o caráter discursivo heteronormativo do gênero pelo poder político na manipulação do discurso «ideologia de gênero» ao excluir a temática de gênero e orientação ao mesmo tempo que elimina o/a Outro/a da política pública de educação no Brasil.

\section{Considerações Finais}

No início desse artigo questionei sobre a centralidade da heteronormatividade do gênero na política de educação no Brasil, tendo como foco a discussão em torno da terceira versão da Base Nacional Comum Curricular, em que o discurso «ideologia de gênero» se tornou emblemático. Busquei demonstrar que o modo como tal discurso foi manipulado reflete de modo absolutamente significativo a centralidade da heteronormatividade do gênero que passou a estar cada vez mais evidente na política de educação com as exclusões da temática gênero e sexualidade desde o Plano Nacional de Educação e posteriormente em vários Planos de educação ao nível dos estados e municípios do país. A centralidade dessa norma do gênero como fixo - e, na prática, heterossexual voltada para a reprodução - é pautada desde um olhar de estranhamento para com aquelas e aqueles que não estão conformes tal modelo, bem como é afirmada com a interdição na política pública de educação ao excluir a temática sobre gênero e sexualidade na Base Nacional Comum Curricular.

A manipulação do discurso «ideologia de gênero» tem sido problemática não apenas porque distorce a realidade ou a nega como histórica, social, cultural e política, mas principalmente porque tem se convertido em uma forma de legitimar a violência aos sujeitos que não se enquadram em um modelo ideal de feminilidade e masculinidade, também ideológico. A força discursiva com a qual se tem empregado tal discurso na política pública de educação no Brasil demonstra ainda a institucionalização dessa violência que no atual governo ilegítimo ${ }^{16} \mathrm{o}$ toma como instrumento político ideológico das forças conservadoras no país. Desse modo, essa política engendra um outro processo civilizatório no qual a escola se constitui o principal aparelho ideológico do Estado. Assim, a manipulação do discurso «ideologia de gênero» pelos grupos conservadores é também uma forma de violência que não pode simplesmente passar pelos debates como «mera opinião ou manifestação de crença». Por fim, a aprovação do documento final da Base Nacional Comum Curricular, ao retirar qualquer menção à temática de gênero e sexua-

16

O atual governo Temer assumiu o poder através de um golpe parlamentar e jurídico com o apoio de uma mídia de guerra, no ano de 2016, que levou ao impeachment da Presidenta eleita, Dilma Rousseff, sem nenhuma comprovação legal da acusação de pedaladas fiscais que vieram mais tarde ser comprovadas como falsas. É preciso notar ainda que também foi um golpe sexista, tamanha a violência de gênero contra a senhora Presidenta ao ponto de ter sido feito apologia ao crime de estupro com a imagem dela em forma de adesivo que circulava nos carros dos apoiadores do golpe a certa altura da pressão contra o governo dela. 
lidade na educação, revela o caráter autoritário da atual política, uma vez que essa política de educação não reflete as necessidades da realidade educacional da sociedade brasileira.

Mas preciso dizer ainda que este trabalho almejou se unir às resistências no meio acadêmico contra uma política de exclusão na educação, e por outra ideologia em que o sexo/gênero sejam conquistas das pessoas no modo como se sentem em relação ao próprio corpo e como um direito coletivo.

\section{Referências bibliográficas}

Althusser, Louis. 1980. Ideologia e aparelhos ideológicos do Estado. Lisboa: Editorial Presença/ Martins Fontes.

Brasil, Governo do. 2017. Base Nacional Comum Curricular. Brasília, DF: Centro Gráfico.

Butler, Judith. (1990) 2016. Problemas de gênero: feminismo e subversão da identidade. 10. a ed. Rio de Janeiro: Civilização Brasileira.

Foucault, Michel. [1970] 1999. A ordem do discurso. 5. a ed. São Paulo: Edições Loyola.

Foucault, Michel. (1976) 2015. História da sexualidade 1: A vontade de saber. 3. ${ }^{a}$ ed. São Paulo: Paz e Terra.

Louro, Guacira Lopes, org. 2000. O corpo educado: Pedagogias da Sexualidade. 2. ${ }^{\text {a }}$ ed. Belo Horizonte: Autêntica.

Louro, Guacira Lopes. 2014. Gênero, sexualidade e educação. Uma perspectiva pós-estruturalista. 16. ${ }^{\text {a }}$ ed. Petrópolis, RJ: Vozes.

Reis, Toni, e Edla Eggert. 2017. «Ideologia de gênero: uma falácia construída sobre os planos de educação brasileiros». Educação \& Sociedade 38 (138): 9-26. https://doi.org/10.1590/ es0101-73302017165522

Scott, Joan W. (1988) 1995. «Gênero: uma categoria útil de análise histórica». Educação \& Realidade 20 (2): 71-99. Disponível em http://seer.ufrgs.br/index.php/educacaoerealidade/ article/view/71721 [Consultado a 12 de novembro de 2017].

Stolcke, Verena. (2003) 2006. «O enigma das interseções: classe, «raça», sexo, sexualidade. A formação dos impérios transatlânticos do século XVI ao XIX». Estudos Feministas 14 (1): 15-42. DOI: https://doi.org/10.1590/S0104-026X2006000100003

Vainfas, Ronaldo. 2010. Trópico dos pecados. Moral, sexualidade e inquisição no Brasil. Rio de Janeiro: Civilização Brasileira.

Vianna, Cláudia Pereira, e Sandra Unbehaum. 2004. «O Gênero nas Políticas Públicas de Educação no Brasil: 1988-2002». Cadernos de Pesquisa 34 (121): 77-104. https://doi. org/10.1590/S0100-15742004000100005

Priscila Freire. Professora Assistente na Escola Normal Superior da Universidade do Estado do Amazonas, em Manaus, Brasil. Mestra em Sociologia e graduada em Ciências Sociais pela Universidade Federal do Amazonas. Doutoranda em Estudos Feministas na Faculdade de Letras da Universidade de Coimbra, Portugal.

Endereço eletrónico: pfrodrigues@uea.edu.br

Artigo recebido a 10 de fevereiro de 2018 e aceite para publicação a 6 de abril de 2018. 